\title{
A comparison of the strength of biodiversity effects across multiple functions
}

Eric Allan ${ }^{1,2}$, Wolfgang W. Weisser ${ }^{1,3}$, Markus Fischer ${ }^{2,4}$, Ernst-Detlef Schulze ${ }^{5}$, Alexandra Weigelt ${ }^{1,6}$, Christiane Roscher ${ }^{5,7}$, Jussi Baade ${ }^{8}$, Romain L. Barnard ${ }^{9}$, Holger Beßler ${ }^{10}$, Nina Buchmann ${ }^{9}$, Anne Ebeling $^{1}$, Nico Eisenhauer ${ }^{1,3,11,12}{ }^{\text {, Christof Engels }}{ }^{10}$, Alexander J. F. Fergus ${ }^{13}$, Gerd Gleixner ${ }^{5}$, Marlén Gubsch $^{13}$, Stefan Halle ${ }^{1}$, Alexandra M. Klein ${ }^{14,15}$, Ilona Kertscher ${ }^{1}$, Annely Kuu ${ }^{1,16}$, Markus Lange ${ }^{1}$, Xavier Le Roux ${ }^{17}$, Sebastian T. Meyer ${ }^{1,3}$, Varvara D. Migunova ${ }^{18}$, Alexandru Milcu ${ }^{19,20}$, Pascal A. Niklaus $^{13}$, Yvonne Oelmann ${ }^{21}$, Esther Pašalić ${ }^{1}$, Jana S. Petermann ${ }^{13,22}$, Franck Poly ${ }^{17}$, Tanja Rottstock $^{4}$, Alexander C. W. Sabais ${ }^{11}$, Christoph Scherber ${ }^{14}$, Michael Scherer-Lorenzen ${ }^{23}$, Stefan Scheu $^{11,12}$, Sibylle Steinbeiss ${ }^{5,24}$, Guido Schwichtenberg ${ }^{25}$, Vicky Temperton ${ }^{5,26}$, Teja Tscharntke ${ }^{14}$, Winfried Voigt ${ }^{1}$, Wolfgang Wilcke ${ }^{27}$, Christian Wirth ${ }^{5,28}$, Bernhard Schmid $^{13}$

${ }^{1}$ Institute of Ecology, Friedrich Schiller University of Jena, Dornburger Str. 159, 07749 Jena, Germany

${ }^{2}$ Institute of Plant Sciences, University of Berne, Altenbergrain 21, 3013 Berne, Switzerland

${ }^{3}$ Technische Universität München, Department für Ökologie und Ökosystemmanagement, Hans-Carlvon-Carlowitz-Platz 2, 85354 Freising, Germany

${ }^{4}$ Department of Botany, Institute of Biochemistry and Biology, University of Potsdam, Maulbeerallee 1, 14469 Potsdam, Germany

${ }^{5}$ Max Planck Institute for Biogeochemistry, Hans-Knoell Str10, 07745 Jena, Germany

${ }^{6}$ Institute for Biology I, University of Leipzig, Johannisallee 21-23, 04103 Leipzig, Germany

${ }^{7}$ UFZ, Helmholtz Centre for Environmental Research, Department of Community Ecology, TheodorLieser-Strasse 4, 06120 Halle, Germany

${ }^{8}$ Institute of Geography, Friedrich Schiller University Jena, Loebdergraben 32, 07743 Jena, Germany

${ }^{9}$ Institute of Plant Sciences, ETH Zurich, Universitaetsstr. 2, 8092 Zurich, Switzerland

${ }^{10}$ Institute of Plant Nutrition, Humboldt University Berlin, Invalidenstr. 42, 10115 Berlin, Germany

${ }^{11}$ Darmstadt University of Technology, Institute of Zoology, Schnittspahnstr. 3, 64287 Darmstadt, Germany 
${ }^{12}$ University of Goettingen, J.F. Blumenbach Institute of Zoology and Anthropology, 37073

Goettingen, Germany

${ }^{13}$ Institute of Evolutionary Biology and Environmental Studies, University of Zürich,

Winterthurerstr.190, 8057 Zurich, Switzerland

${ }^{14}$ University of Göttingen, Agroecology, Department of Crop Sciences, Waldweg 26, 37073

Göttingen, Germany

${ }^{15}$ Institute of Ecology, Ecosystem Functions, Leuphana University of Lüneburg, Germany

${ }^{16}$ Tallinn University of Technology, Tartu College, Puiestee 78, 51008 Tartu, Estonia.

${ }^{17}$ Université de Lyon, INRA, CNRS, Université Lyon 1, Microbial Ecology Centre (UMR 5557

CNRS, USC 1193 INRA), bat. G. Mendel, 43 boulevard du 11 Novembre 1918, 69622 Villeurbanne, France.

${ }^{18}$ K.I. Skryabin All-Russian Institute of Helminthology, Moscow, Russia

${ }^{19}$ Imperial College London, Silwood Park, Buckhurst Road, Ascot SL5 7PY, UK

${ }^{20}$ CNRS Ecotron, 1 Chemin du Rioux, Campus Baillarguet, 34980 Montferrier-sur-Lez, France

${ }^{21}$ Geographic Inst., Professorship of Soil Geography/Soil Science, Johannes Gutenberg Univ., JohannJoachim-Becherweg 21, 55128 Mainz, Germany

${ }^{22}$ Institute of Biology, Freie Universität Berlin, Königin-Luise-Str. 1-3, 14195 Berlin, Germany

${ }^{23}$ Faculty of Biology, University of Freiburg, Schaenzlestr. 1, 79104 Freiburg, Germany

${ }^{24}$ Helmholtz Centre Munich, German Research Center for Environmental Health (GmbH), Ingolstaedter Landstr. 1, 85764 Neuherberg, Germany

${ }^{25}$ Helmholtz Centre for Environmental Research (UFZ), Permoserstraße 15, 04318 Leipzig, Germany

${ }^{26}$ Phytosphere Institute ICG-3, Forschungszentrum Juelich GmbH, 52425 Juelich, Germany

${ }^{27}$ Soil Science Group, Geographic Institute, University of Bern, Hallerstrasse 12, 3012 Bern

${ }^{28}$ Department of Special Botany and Functional Biodiversity Research, Institute of Biology I, University of Leipzig, Johannisallee 21-23, 04103 Leipzig, Germany. 


\begin{abstract}
In order to predict which ecosystem functions are most at risk from biodiversity loss, meta-analyses have generalised results from biodiversity experiments over different sites and ecosystem types. In contrast comparing the strength of biodiversity effects across a large number of ecosystem processes measured in a single experiment permits more direct comparisons. Here we present an analysis of 418 separate measures of 38 ecosystem processes. Overall $45 \%$ of processes were significantly affected by plant species richness, suggesting that whilst diversity affects a large number of processes not all respond to biodiversity. We therefore compared the strength of plant diversity effects between different categories of ecosystem processes: grouping processes according to the year of measurement, their biogeochemical cycle, trophic level and compartment (above- or belowground) and according to whether they were measures of biodiversity or other ecosystem processes, biotic or abiotic and static or dynamic. Overall, and for several individual processes, we found that biodiversity effects became stronger over time. Measures of the carbon cycle were also affected more strongly by plant species richness than were the measures associated with the nitrogen cycle. Further we found greater plant species richness effects on measures of biodiversity than on other processes. The differential effects of plant diversity on the various types of ecosystem processes indicate that future research and political effort should shift from a general debate about whether biodiversity loss impairs ecosystem functions, to focussing on the specific functions of interest and ways to preserve them individually or in combination.
\end{abstract}

Keywords: biodiversity, bottom-up effects, carbon cycling, ecological synthesis, ecosystem functioning, ecosystem processes, functional groups, grasslands, Jena Experiment, nitrogen cycling. 


\section{Introduction}

Understanding the relationship between biodiversity and ecosystem functioning is of great theoretical interest for understanding the processes structuring communities and of practical importance to predict the effect of human-induced biodiversity loss. Numerous experiments have demonstrated that a range of ecosystem functions depend on biodiversity (usually species richness) (Hector et al. 1999; Loreau et al. 2001; Tilman et al. 2001; Hooper et al. 2005). In addition, certain key functional groups, such as grasses and legumes in grassland ecosystems, can also have large effects on ecosystem functioning (Hooper et al. 2005). However it is still not clear which particular ecosystem variables are most strongly affected by species richness or functional group composition. This question is important as it relates to our understanding of the mechanisms that underlie the biodiversity-ecosystem functioning relationship. For biodiversity research to be predictive, it is therefore necessary to move forward from showing that biodiversity has an effect on functioning to investigating which functions are most strongly affected.

Recently meta-analyses and syntheses have attempted to answer this question by comparing the strength of biodiversity effects on different processes, across different experiments (Balvanera et al. 2006; Cardinale et al. 2006; Schmid et al. 2009; Cardinale et al. 2011; Hooper et al. 2012). This generalises across sites; but processes measured in different experiments may not always be directly comparable. An alternative approach is to synthesize data from a single experiment and to investigate the effect of biodiversity on different processes measured on the same plots (Proulx et al. 2010; Scherber et al. 2010; Rzanny and Voigt 2012). This has the advantage that different variables and ecosystem functions can be directly compared, without being affected by variance between experimental sites. We therefore use this approach here and present a large analysis of results from a German biodiversity experiment, the Jena Experiment (Roscher et al. 2004). We include 418 measures of 38 ecosystem processes.

The length of time an experiment has been running is likely to be an important factor affecting the strength of biodiversity effects found. Biodiversity effects have been shown to become stronger over time, as complementary interactions between species become more important in longterm experiments (Cardinale et al. 2007) resulting in less saturating relationships between biodiversity 
and function (Reich et al. 2012). Studies have so far focussed on individual variables such as biomass production and it is not clear if this pattern holds across a wider range of ecosystem processes.

The interactions between carbon, nutrient and water cycles are fundamental to ecosystem functioning (Schulze and Zwölfer 1994), and it is therefore important to know whether they are affected differently by biodiversity loss. Loss of biodiversity has been shown to reduce biomass production (Hector et al. 1999; Tilman et al. 2001; Marquard et al. 2009), and affect other pools and fluxes of the carbon (Hooper et al. 2005; Fornara and Tilman 2008; Steinbeiss et al. 2008) and nitrogen cycle (Tilman et al. 1996; Scherer-Lorenzen et al. 2003; Hooper et al. 2005; Palmborg et al. 2005; Oelmann et al. 2011). A relationship between plant biomass production and nutrient uptake would be expected in ecosystems strongly limited by nutrients where resource-use complementarity for nutrients may be the dominant mechanism driving the species richness-biomass relationship (Tilman et al. 2001). However resource-use complementarity for nutrients might not be so important in productive systems or those limited by factors other than nutrient availability, for instance, if plant enemies and not nutrients limit biomass production in low diversity communities (Maron et al. 2010; Schnitzer et al. 2011). In such systems plant diversity might have large effects on biomass production and carbon cycling but smaller effects on nutrient uptake and other measures of nutrient cycling.

As well as potential differences between biogeochemical cycles, plant diversity effects might also vary between other classes of ecosystem process. Plant diversity has been shown to have a larger effect on above- than belowground animal groups in the Jena Experiment (Scherber et al. 2010) and this may be because belowground organism groups respond more slowly (Eisenhauer et al. 2010) or in a more idiosyncratic fashion to plant diversity(de Deyn and van der Putten 2005). Broadening the scope beyond organisms groups, belowground processes in general might be less strongly affected by plant species richness than are aboveground processes because the belowground processes are principally microbially mediated and therefore less directly affected by plants (Hooper et al. 2005). Similarly, plant diversity might have larger effects on direct (biotic) measures of other organism groups than on abiotic measures, which are mediated by, but which are not direct measures of, organisms. In particular strong effects of plant species richness on direct measures of animals, such as the abundance and diversity of insects, are to be expected due to co-evolutionary interactions between 
plants and animals (e.g. Haddad et al. 2009; Eisenhauer et al. 2011) but this might not be true for plant species richness effects on abiotic processes more indirectly associated with organisms such as biogeochemical cycling. Finally, the contrast between measures of fluxes and measures of standing stocks has been suggested as a major distinction between types of functions (Pacala and Kinzig 2001). Many of these contrasts, between biogeochemical cycles, above and belowground variables and biotic and abiotic variables will be at least partially confounded, for instance many nutrient measures are likely to be abiotic and belowground. Therefore only a large analysis with many measures of each category of process can determine which contrasts are the most important for predicting differences in plant diversity effects.

Understanding the effect of changes in plant diversity for other trophic levels is important for predicting the impact of plant species extinctions on total biodiversity. A previous synthesis of results from the Jena Experiment (Scherber et al. 2010) investigated the effects of plant species richness on the abundance and diversity of other trophic levels and found that the response of different organisms to plant diversity varied strongly. Herbivores were more likely to show a significant response to plant species richness than were predators, parasitoids or omnivores. This suggests strong bottom-up effects on multitrophic interaction networks and shows that plant diversity effects on higher trophic levels are indirectly mediated through bottom-up trophic cascades. Plant species richness might also have larger effects on animal species richness than on abundance, if rare animal species are only present in diverse plant communities. The analysis by Scherber et al. (Scherber et al. 2010) showed this pattern for a number of invertebrate groups. More generally plant species richness might have its strongest effects on the diversities of other groups of organisms. Here, we extend the analysis of Scherber et al. (Scherber et al. 2010) by including a larger number (418) of measures of ecosystem processes that come from all compartments of the ecosystem, i.e. our dataset is not restricted to measures of animal groups. For instance in the comparison of plant species richness effects between trophic levels we include the producer trophic level and when comparing plant species richness effects between diversity and other measures we additionally test whether plant species richness has a stronger effect on measures of animal diversity than on measures such as plant biomass production. We can therefore 
test whether the patterns of stronger plant diversity effects on herbivores and on the species richness of animal groups hold when the analysis is extended to include a wider range of ecosystem processes.

In addition to effects of plant species richness on ecosystem processes, the presence of key plant functional groups may be important for driving certain functions. It has been suggested that soil processes such as decomposition, nutrient uptake and nutrient retention are affected more by the functional traits of dominant species than by species richness per se (Hooper et al. 2005). Functional composition, and the presence of legumes in particular (Vitousek and Howarth 1991; Temperton et al. 2007), could therefore have a larger effect on nutrient cycling than plant species richness does.

To investigate variation in the strength of plant species richness and functional group effects between different types of ecosystem processes, we grouped measured variables into a number of categories (Table 1) associated with basic ecological processes. For each of the measures analysed here, we quantified the effect size of species richness and functional group (legume and grass) presence using $Z r$-values (Balvanera et al. 2006). We then analysed the $Z r$-values for species richness and presence of legumes and grasses using the ecosystem process categories (Table 1) as explanatory terms (Balvanera et al. 2006; Schmid et al. 2009). We tested the following hypotheses:

1) Plant species richness effects increase in strength over time.

2) Plant species richness has stronger effects on carbon than on nutrient cycling.

3) Plant species richness has larger effects on processes measured above- than belowground.

4) Plant species richness has strong bottom up effects on higher trophic levels and these are larger on lower trophic levels (herbivores vs. carnivores).

5) Plant diversity has its strongest effects on the species richness of animal groups.

6) Functional groups such as legumes and grasses have stronger effects on nutrient cycling than plant species richness does. 


\section{Methods}

\section{Experimental Design}

The measurements reported here were gathered between 2002 and 2008 in the Jena Experiment, a grassland biodiversity experiment in Germany which controlled the number of plant species, functional groups and plant functional identity in 82 plots, each $20 \times 20 \mathrm{~m}$, in a randomized block design. Plants belonged to one of four functional groups (for details see Roscher et al. 2004): legumes, grasses, tall herbs and small herbs and the presence/absence of these functional groups was manipulated factorially with species richness. Thus, the design included communities of single functional groups with 1-16 species as well as communities of 16 species ranging from 1-4 functional groups. In our analyses we focus on the effects of legumes and grasses because many studies have identified these as important functional groups and because the herb functional groups might not be comparable with groups in other grasslands. Plots were seeded in May 2002 with 1, 2, 4, 8, 16 or 60 perennial grassland plant species, with 16, 16, 16, 16, 14 and 4 replicates respectively. Plot compositions were randomly chosen from 60 plant species typical for local Arrhenatherum grasslands. Plots were maintained by mowing, weeding and where possible by applying grass- or herb-specific herbicides, all twice per year (Roscher et al. 2004).

\section{The dataset}

We included 418 measurements of ecosystem processes in our analysis. All measurements were taken independently, i.e. none of the measurements are direct functions of other measures. The 418 measures were nested within 119 variables and these variables were nested within 38 ecosystem processes (see Table S1). The ecosystem processes were in turn nested within 6 larger categories of processes, such as carbon- vs. nutrient-related processes (shown in Table 1). These groups were partially crossed with each other, e.g. carbon variables could be measured above or below ground and could be biotic or abiotic. Our analysis tested for differences between these larger groups. In order to conduct a global analysis, all variables were classified according to these 6 categories of processes. As the assignment of certain variables, such as plant biomass, to a particular biogeochemical cycle is not trivial we further analysed a smaller dataset composed of measures that could be unambiguously 
assigned to one or another cycle, see below. Many of the 119 variables had been measured in multiple years and/or at multiple soil depths and we included all of these multiple measures in our analyses in order to test for trends in the strength of effects over time and soil depth. However, we used mixed modelling to account for the nestedness of measurements and the spatial and temporal autocorrelation of variables; see below. Most processes and variables were measured between 2003 and 2006 (2002: 6 \& 9; 2003: $21 \& 48 ; 2004: 23 \& 45 ; 2005: 19 \& 58 ; 2006: 20 \& 38 ; 2007: 13 \& 21$, and 2008: $1 \& 8$ processes \& variables respectively).

\section{Statistical analysis}

Deriving $Z r$-values and significances for the individual measures

We calculated effects of plant species richness, or the presence of functional groups, on each of these 418 measures as the standardized correlation coefficient $Z r$, an effect-size value often used in meta-analysis (Gurevitch and Hedges 1999). $Z r$-values were extracted from analysis of variance (ANOVA) models using the following formula:

(1: ANOVA model)

block $+\log ($ species richness $)+$ legumes + grasses + tall herbs + small herbs

$r$-values were calculated as the proportion of total sum of squares explained by species richness, legume or grass presence and were converted with a Z-transformation to improve normality, using the formula (Rosenberg et al. 2000):

$Z r=0.5 \ln ((1+r) /(1-r))$

Sequential (type-I) sums of squares were used (Schmid et al. 2009), which means effects of legumes were corrected for species richness and effects of grasses were corrected for species richness and legumes. According to the design of the Jena Experiment these explanatory factors are as nearly as 
possible, but not perfectly, orthogonal to each other (Roscher et al. 2004). All analyses were conducted using the statistical package R 2.14 (R Development Core Team 2010).

\section{Comparing diversity effects between different categories of ecosystem process}

To compare different categories of process we then analysed $Z r$-values, related to plant species richness and functional group effects, as a function of the ecosystem process categories in Table 1. This analysis is essentially a derived variable analysis and is therefore equivalent to a repeated measures analysis using the original data. It is also similar to a meta-analysis in which data taken from a single experiment are analysed to show differences among within-experiment explanatory terms but is different to standard meta-analysis conducted on data from many experiments. Here each particular ecosystem process category (for instance all measures related to the carbon cycle) is represented by several variables which can be considered as independent replicate measures for the purpose of comparing between different groups within the ecosystem process category (e.g. comparing carbon and nitrogen measures). Of course, however, unlike in a typical metaanalysis, but as in all experimental studies, our conclusions will only apply to this one experiment.

\section{Mixed modelling}

Linear mixed-models (fitted using the lme4 package Bates et al. 2011 in R) were used to analyse the $Z r$-values. The different ecosystem process categories presented in Table 1 were used as fixed explanatory terms. We used random effects to account for the nestedness of our data: measures nested within ecosystem variables, ecosystem variables within ecosystem processes. Mixed models included ecosystem variable identity as a random effect with 119 levels (Variable in model formula, column 2 in Table S1). Crossed with this term, were random effects for year and soil depth (many soil measures were taken at different depths; all aboveground measures were coded as 0 depth). Ecosystem process (Fig. 1) was included as a random effect with 38 levels and we also included the interaction between ecosystem process and year as another random effect; this had 109 levels. In order to test for temporal or spatial trends in the $Z r$-values, we included linear contrasts for year and soil depth as fixed terms. We also conducted a jackknife analysis (see below) to check that our results were robust to any 
additional sources of non-independence between measures. As some measures were only taken on a subset of plots, the $Z r$-values were also weighted by the proportion of plots on which the original measure was taken.

All fixed terms (the explanatory terms in Table 1 as well as year and soil depth) were fitted both individually and in a combined analysis, i.e. they were removed from the full model (equation 2) and added to the minimal model (equation 3 ). As a conservative test, we only considered fixed effects significant if they were significant in both cases, i.e. when added to the null model and when removed from the full model. We used these stringent rules because the fixed effects were not fully orthogonal to each other and we wanted to ensure that our conclusions would hold both if an explanatory term of interest was, or was not, corrected for other, correlated explanatory terms. Significance for each term was assessed by model comparison using likelihood ratio (L-ratio) tests (Crawley 2007). In addition, significance of terms was assessed using Markov Chain Monte Carlo sampling (Baayen et al. 2008), for terms fitted in the full model, which did not change the significance of any terms. The full and null models (using the syntax of the lme4 package Bates et al. 2011) are shown below; see Table 1 for a description of the fixed effect terms and Table $\mathrm{S} 1$ for the assignment of variables to the different fixed and random effect terms:

(2: full model)

year(linear) + SoilDepth(linear) + BiogeochemicalCycle + TrophicLevel + DiversityOthers + AbioticBiotic + Compartment + StaticDynamic $+(1 \mid$ Variable $)+(1 \mid$ SoilDepth $)+(1 \mid$ year $)+$ (1|EcosystemProcess $)+(1 \mid$ EcoystemProcess:year $)$

(3: minimal model)

intercept $+(1 \mid$ Variable $)+(1 \mid$ SoilDepth $)+(1 \mid$ year $)+(1 \mid$ EcosystemProcess $)+$ (1|EcoystemProcess:year)

where "(1|...)" indicates the random effects, the model estimates the variance between the means for each level of the random effect (all random effects are categorical here). 


\section{Further analyses with biogeochemical cycle}

In order to explore species richness effects on different biogeochemical cycles further, the analysis was restricted to variables that were direct measures of carbon, nutrients or water. This analysis, therefore, excluded variables such as plant biomass or animal abundances, which could be associated with multiple biogeochemical cycles (see Table S1 for list of excluded variables), and was conducted with 67 carbon measures, 83 nutrient measures and 38 water measures. Equation 2 was used to fit these models but without the terms "TrophicLevel" and "DiversityOthers", as there were no measures of animals included. We also repeated this analysis including aboveground pool sizes of carbon and nitrogen in plant tissue (shoot and root), instead of measures of carbon and nitrogen concentrations in plant biomass. Pool size is calculated as concentration $\times$ plant biomass. Note that we included concentrations and not pool sizes in the main analysis because pool sizes are closely correlated with plant biomass and would therefore not be independently measured variables, as they represent linear combinations of concentrations and biomass.

Differences between carbon $(\mathrm{C})$ and nutrient $(\mathrm{N})$ cycles could be due to differences in the size or in the sign of the $Z r$ values. For some variables it could be argued that a negative sign indicates a positive effect of diversity on function. It is clear that a positive correlation between species richness and biomass equates to a positive effect on function but in other cases this might not be straightforward. For instance, lower soil nitrogen levels might correspond to increased plant nitrogen uptake, which would be associated with an increase in functioning. However, lower soil nitrogen might also result from a decreased mineralization rate, which would imply a decrease in functioning. To avoid these problems we analysed $Z r$-values with their original sign in the main analysis. However we conducted additional analyses in which we varied the sign. Firstly, we repeated the analysis with the sign reversed for soil $\mathrm{N}$ variables: if the main difference between $\mathrm{C}$ and $\mathrm{N}$ variables is that $\mathrm{N}$ variables are significantly negatively affected by plant species richness whereas $\mathrm{C}$ variables are significantly positively affected, this analysis would show no difference between the two. Secondly, as a more conservative test we repeated the analysis of direct measures of carbon, nutrients and water, including pool sizes rather than concentrations and reversing the sign for all those ecosystem variables that had a negative mean $Z r$-value (these were: soil nitrate, soil $\delta 15 \mathrm{~N}$ values, soil phosphorus, plant 
$\delta 15 \mathrm{~N}$ values and methane oxidation). Therefore, in this analysis all ecosystem variables analysed had a positive mean $Z r$-value, although clearly some of the individual measures of each ecosystem variable were still negative. If there are certain variables which are significantly negatively affected by plant diversity (such as soil nitrate where a negative value could indicate high functioning), and these drive the difference between $\mathrm{C}$ and $\mathrm{N}$ cycles, they would be significantly positively affected in this analysis and again the difference between $\mathrm{C}$ and $\mathrm{N}$ cycles would disappear. Note that it is not possible to analyse absolute $Z r$-values because this would inflate effect sizes. Ecosystem variables that are not significantly affected by diversity should on average have a $\mathrm{Zr}$-value of zero, corresponding to a mix of slightly positive and slightly negative $Z r$-values for the different measures. Absolute $Z r$-values would mean ecosystem variables always had a positive mean $\mathrm{Zr}$-value and thus would appear to be correlated with diversity even if they were not.

A larger number of carbon-related measures (294) had been taken compared with nutrientrelated measures (83) or water-related measures (41). To assess whether this unequal sampling affected the significance of the biogeochemical cycle term, the number of carbon and nutrient-related measures was equalised with the number of water-related variables by randomly selecting 41 carbonrelated and 41 nitrogen-related measures. This process of jackknifing also provides a much more conservative test, as only 123 measures are included instead of 418 . The analysis was repeated 1000 times with different sets of randomly selected carbon and nutrient variables using the following formula:

(4: Jackknife model)

year(linear $)+$ SoilDepth $($ linear $)+$ BiogeochemicalCycle $+(1 \mid$ Variable $)+(1 \mid$ SoilDepth $)+(1 \mid$ year $)+$ $(1 \mid$ EcosystemProcess $)+(1 \mid$ EcoystemProcess:year $)$

Significance of the term biogeochemical cycle was therefore assessed by comparing models fitted with (4) to models fitted with (3), using L-ratio tests.

\section{Results}


Across all processes species richness had on average a positive effect (mean effect size \pm one standard error $=0.08 \pm 0.05$; this is the intercept from a linear mixed model without any fixed effects (equation 3) and is therefore corrected for the random effects). To determine the proportion of ecosystem processes significantly affected by plant species richness, confidence intervals were calculated around the mean $Z r$-value for each of the 38 ecosystem processes (see Fig. 1). Of these 17 had confidence intervals which did not cross 0 , suggesting that nearly half (45\%) of processes were significantly affected by species richness on average.

\section{Change in species richness effects over time and soil depth}

The linear terms for year and soil depth were significant in the analysis of species richness $\mathrm{Zr}$ values: the slope for year was positive $(0.026 \pm 0.008)$ indicating an increase in the magnitude of $Z r$ values, and thus in the effects of species richness, over time from 0.02 in 2002 to 0.19 in 2008, Fig. 2a. Plant species richness effects increased over time significantly for plant biomass, soil water contents and the abundance of decomposers and marginally so for soil nitrate Fig. 3a. Plant species richness effects decreased significantly over time for the abundance of carnivores and marginally so for the abundance of herbivores. The slope for the soil depth term was negative $(-0.0022 \pm 0.0007)$, indicating a decrease in the strength of the species richness effect with increasing soil depth, Fig. 2b. Plant species richness effects decreased with soil depth significantly for soil water and soil nitrate, Fig. 3b.

\section{Differences between ecosystem processes categories}

Two of the ecosystem process categories showed significant overall species richness effects: biogeochemical cycle and the contrast between diversity measures and measures of other processes (Fig. 1a; Table 2). On average, plant species richness had a significantly positive effect on variables related to the carbon cycle (confidence intervals did not overlap 0) but non-significant overall effects on nutrient- (mostly nitrogen) and water-cycle related variables (Fig. 4a, see also Fig.1a for the individual processes contained in the categories). Most variables associated with the carbon cycle, including biomass of plants, abundance of animals and soil organic carbon storage, were positively correlated with diversity, see Fig. 1a, while among the water variables species richness effects 
declined with increasing soil depth so that only water content of the topsoil was significantly positively affected, see Fig. $1 \mathrm{a}$ and $2 \mathrm{~b}$. In contrast to the overall positive effects on carbon and water variables, most measures related to the nitrogen cycle had small $Z r$-values and their confidence intervals included zero, suggesting zero or small effects of plant species richness on soil nitrogen pools and fluxes (Fig. 1a). The $Z r$-values for species richness effects were also significantly affected by the variable diversity/others because plant species richness had stronger effects on the diversities of other organisms $(0.35 \pm 0.09)$ than on other measures such as animal abundances, stock sizes of abiotic pools, and flux measures $(0.06 \pm 0.05)$.

\section{Further analyses with biogeochemical cycle}

We also carried out a number of sensitivity analyses to explore the differences in the size of species richness effects between different biogeochemical cycles. When only variables that were direct measures of carbon, nutrients or water (i.e. excluding biomass and abundance measures, see Table S1) were included in the comparison between the biogeochemical cycle groups, this resulted in an increase in the significance of the term, from $\chi^{2}=5.8, p=0.03$, with all variables included, to $\chi^{2}=9.1 ; p=0.01$ with only direct measures (both p-values for deletion of the term from the full model, Fig. 4b). In the analysis of direct measures, plant species richness had a significantly positive effect on carbon measures, whereas, overall, plant species richness did not have a significant effect on nutrient measures (Fig. 4b). When aboveground pool sizes of nitrogen and carbon in plant tissue were used instead of concentrations in this analysis, the comparison between groups remained significant on deletion from the full model $\left(\chi^{2}=6.5 \mathrm{p}=0.04\right)$ and marginally so when biogeochemical cycle was tested on its own $\left(\chi^{2}=4.8, p=0.09\right)$. These results together further support stronger species richness effects on the carbon than the nutrient cycle.

When the analysis of $Z r$-values was carried out with the sign for the soil nutrient variables reversed, the biogeochemical cycle term was still significant (addition $\chi^{2}=8.2, p=0.01$; deletion $\chi^{2}=6.6, \mathrm{p}=0.03$ ). When the sign was reversed for only those soil variables with a negative mean $\mathrm{Zr}$ value, biogeochemical cycle also remained significant (addition $\chi^{2}=6.9, \mathrm{p}=0.03$; deletion $\chi^{2}=8.2, \mathrm{p}=$ 0.02). When direct measures of carbon and nutrients were analysed, using pool sizes rather than 
concentrations and with the sign for all variables with a negative mean $Z r$-value reversed, biogeochemical cycle remained significant when deleted from the full model $\left(\chi^{2}=8.2 \mathrm{p}=0.01\right)$, although not when tested alone $\left(\chi^{2}=2.6, p=0.27\right)$. These results show that the contrast in plant species richness effects between biogeochemical cycles is not caused by a difference in the direction of the effect (e.g. the contrast is not caused by strong negative effects of plant species richness on nutrient measures and strong positive effects of plant species richness on carbon measures) rather the contrast is caused by a difference in the size of the effects, which are stronger for carbon measures and weaker for nutrient measures.

When the analysis of biogeochemical cycles was repeated using equal numbers of carbon-, nutrient- and water-related measures, the biogeochemical cycle term was significant in 836 out of 1000 runs. This suggests that unequal sampling did not affect the results. It also suggests that the result was robust to a decrease in the degrees of freedom for testing the effect of biogeochemical cycle, as it generally remained significant when only $30 \%$ of the variables were included. This indicates that any additional non-independence between variables, not accounted for by our random effect structure, did not bias the result for the biogeochemical cycle term.

Together, our additional sensitivity analyses on the differences between biogeochemical cycles support larger overall species richness effects on the carbon cycle and small or variable effects on the nutrient and water cycles.

\section{Effects of functional group presence}

None of the grouping variables significantly affected the $Z r$-values for effects of grasses or legumes (Fig. 1b-c and Table 2), although the strength of grass effects increased with time (slope $0.011 \pm 0.004)$. Comparing the strength of the effects of functional group presence with the strength of species richness effects, showed that for nutrient measures legume effects were larger than species richness effects: the average $Z r$ - value for legume effects on nutrient measures was $0.13 \pm 0.07$ compared to a species richness $Z r$-value of $-0.05 \pm 0.07$. Most measures of nutrients increased with legume presence, in particular nitrogen concentrations in plants and microbes as well as the nitrate pool size (Fig. 1b). Grass effects on nutrient measures were also stronger than species richness effects 
and contrary to legume effects were more negative: the average $Z r$-value was $-0.08 \pm 0.04$. Grass presence had negative effects on nitrogen tissue concentrations and nitrate pools (Fig. 1c). For carbon measures, species richness effects were larger $(0.15 \pm 0.05)$ than were legume $(0.07 \pm 0.04)$ or grass $(0.008 \pm 0.01)$ effects.

\section{Discussion}

Overall ecosystem processes were positively correlated with plant diversity. The average $Z r$ value for species richness effects was $0.08 \pm 0.05$, slightly higher than the figure of 0.039 reported for grassland studies in a meta-analysis by Balvanera et al. (Balvanera et al. 2006). Our results show that plant species richness effects are on average positive across a wide range of ecosystem processes; however there was substantial variability in the effects, given the wide range of different ecosystem processes measured. Recent studies have shown that biodiversity effects on biomass can be comparable to the effects of other environmental change drivers (Hooper et al. 2012; Tilman et al. 2012) and it will therefore be important to compare the effects of biodiversity and other environmental change drivers on a larger number of ecosystem processes to understand the relative importance of biodiversity.

We found that around $45 \%$ of ecosystem processes were significantly affected by plant species richness. Plant species richness effects are therefore important for a large number of ecosystem processes, though not all processes respond. It is, however, possible that simultaneously maintaining high levels of multifunctionality of the other (non-responding) processes would require high plant diversity (Hector and Bagchi 2007; Isbell et al. 2011). We investigate the causes of the large variation in the strength of plant species richness effects between ecosystem processes, to identify which types of processes respond strongly.

\section{Trends over time}

The magnitude of the species richness effect increased since the start of the experiment. Other studies have shown that biodiversity effects on biomass production (Cardinale et al. 2007; Marquard et al. 2009; Reich et al. 2012), on soil nitrogen variables (Oelmann et al. 2011) and on the soil biota (Eisenhauer et al. 2010) become stronger with time. These results agree with ours (Fig. 2a). In 
addition, we find that plant diversity effects increased over time for soil water content. The soil organisms may have taken several years to colonise the experimental communities, explaining the increasing plant diversity effects over time (Eisenhauer et al. 2011). Different mechanisms are likely to be behind the effects for the other ecosystem processes. Functional redundancy between species has been shown to decrease over time resulting in less strongly saturating species richness biomass relationships over time (Reich et al. 2012). This may be due to an increase in positive, complementary interactions between species over time, and turnover between functionally dissimilar species (Allan et al. 2011), resulting in greater functional diversity in more mature plant communities (Reich et al. 2012). This in turn may have been associated with greater biomass production as well as reduced water loss from diverse plots. Our analysis shows a strong pattern of increasing biodiversity effects over time for a number of different ecosystem processes.

\section{Differences between biogeochemical cycles}

Species richness effects differed between groups of variables belonging to different biogeochemical cycles. On average, we found that plant species richness had significantly positive effects on carbon variables but no significant effects on nutrient measures (mostly nitrogen). Soil carbon storage was increased in species rich communities perhaps due to both increased plant inputs and increased microbial respiration (Steinbeiss et al. 2008). A previous meta-analysis of biodiversity effects on function did not find this difference in effect size between biogeochemical cycles (Balvanera et al. 2006) but it has been suggested that changes in vegetation composition may cause imbalance between biogeochemical cycles (Schulze and Zwölfer 1994). Our results suggest that the contrast between carbon and nutrient measures was more important for predicting the strength of plant species richness effects on ecosystem function than was the contrast between abiotic and biotic measures, measures of pools and fluxes or above- and belowground measures. Our analysis therefore suggests that, despite the usual close coupling of nitrogen and carbon cycling, the loss of plant biodiversity may have larger effects on the carbon than the nitrogen cycle.

There are a number of possible reasons for the difference in plant species richness effects between carbon and nutrient cycles. Plant species richness might have larger effects on carbon than 
nitrogen cycling because overyielding, the increased biomass production of more species-rich communities compared with less diverse communities, was driven by mechanisms other than resource-use complementarity. If the plant species richness biomass relationship is driven by resource complementarity for nitrogen, plant species richness effects on carbon and on nitrogen measures would be expected to be similar. However, direct measurements of belowground niche differentiation have not yet provided strong evidence for resource use complementarity in diverse mixtures (von Felten et al. 2009). Further, in productive sites, diverse communities may be limited by light competition (Roscher et al. 2011) which causes plants to invest more in N-poor structural tissue (Hirose and Werger 1995), therefore reducing nitrogen concentrations in aboveground biomass in species rich communities. The plant species richness-biomass relationship might also be driven by plant natural enemies, resulting in weaker effects on nutrients than on carbon. Soil fungal pathogens can drive the diversity-productivity relationship by causing large reductions in biomass in speciespoor plant communities (Maron et al. 2010; Schnitzer et al. 2011). In low diversity communities, soil pathogens might also reduce rooting volume therefore reducing uptake of nutrients as well as carbon production (de Kroon et al. 2012). However, aboveground fungal pathogens or herbivores could act in a similar way to belowground pathogens: infection by foliar fungal pathogens strongly decreases with species richness in our experiment (Fig. 1a). These aboveground enemies could remove substantial quantities of biomass in low-diversity communities (Carson et al. 2004; Allan et al. 2010) and therefore drive the species richness biomass relationship. In general it may be the case that where the species richness biomass relationship is driven by niche complementarity for nitrogen, plant species richness has strong effects on both carbon and nitrogen cycling but if the plant species richness biomass relationship is driven by natural enemies then plant species richness might have relatively weaker effects on nitrogen than on carbon cycling.

\section{Differences between above- and belowground processes}

The strength of biodiversity effects decreased with increasing soil depth but contrary to our expectations the contrast between above- and belowground processes was not significant. Scherber et al. (Scherber et al. 2010) found smaller plant species richness effects on belowground invertebrates but this cannot explain the soil depth effect as belowground organisms were not measured at different 
depths. Plant species richness has also been suggested to influence microbially mediated soil processes less strongly than plant-mediated aboveground productivity (Hooper et al. 2005), although this distinction may be less important here as we also find smaller plant diversity effects on root biomass as opposed to shoot biomass (Bessler et al. 2009). We find that processes, such as soil water and nutrient contents, measured at greater soil depths, are affected less strongly by plant diversity. Smaller plant diversity effects on nutrients at greater soil depths may result from reduced plant uptake of nutrients or reduced plant inputs to the soil at depths where root biomass is lower (Jackson et al. 1996). The positive plant diversity effects on topsoil water contents (and smaller effects at greater soil depths) probably arise through increased shading and therefore reduced evaporation in diverse plant communities (Rosenkranz et al. 2012). Our results suggest that the above-belowground contrast is therefore less important for predicting the strength of plant diversity effects and that instead plant diversity effects decline continuously with increasing soil depth.

\section{Bottom-up effects on higher trophic levels}

Our results provide strong evidence for positive bottom-up effects of plant diversity on herbivore, pollinator, pathogen, decomposer and carnivore groups. This result agrees with other, partial, syntheses of Jena Experiment results (Scherber et al. 2010; Eisenhauer et al. 2011), although unlike the analysis by Scherber et al. (Scherber et al. 2010), here we find no consistent differences between plant species richness effects for different trophic levels, which also suggests that our analysis is quite conservative. There are a number of possible reasons for the positive bottom-up effects of plant diversity. A diverse plant community may support a greater diversity of specialist herbivores and/or generalist herbivores might benefit from the increased diversity of plant resources in more species-rich plant communities (Resource Specialization Hypothesis) (Siemann 1998; Haddad et al. 2009). It is also possible that a greater total quantity of resources in diverse plant communities could support a greater number and biomass of herbivore individuals and therefore a greater diversity of species (More Individuals Hypothesis) (Haddad et al. 2009). The latter hypothesis may be less likely here because we found that the diversities of animal groups were more strongly influenced by plant species richness than were abundances of these animals, which would not be expected if plant 
diversity primarily increases herbivore abundance and secondarily herbivore species richness. Note that we have no measures of herbivore biomass: a recent analysis provided strong evidence for the More Individuals Hypothesis but this was mediated by herbivore biomass not herbivore abundance (Borer et al. 2012). The stronger plant diversity effects on animal species richness as compared to animal abundance might be due to a greater number of rare insect species in high diversity plant communities (Haddad et al. 2009). Declining plant diversity should lead to a faster decline in species richness than in total abundance of animal groups if rarer animal species are the first to be affected by plant diversity loss. The especially strong plant species richness effects on the diversities of other organisms imply that ecosystem services which depend on animal diversity, such as provision of natural enemies and pollinators, are likely to be particularly threatened by loss of plant species (Blüthgen and Klein 2011).

\section{Functional group effects}

Functional group composition also had strong effects on certain ecosystem processes, in particular those associated with the nitrogen cycle. In general, functional group effects on nitrogen cycling were stronger than species richness effects, even though functional group presence was fitted after species richness in the ANOVA models (see equation 1). Our results agree with a number of other experiments, which have shown strong functional group effects (Hooper and Vitousek 1998; Scherer-Lorenzen et al. 2003; Palmborg et al. 2005; Temperton et al. 2007). Most measures of nitrogen increased with legume presence because legumes fix atmospheric nitrogen and therefore increase nitrogen stocks (Craine et al. 2002; Oelmann et al. 2007; Temperton et al. 2007). Grass presence had negative effects on nitrogen measures most likely because grasses are good competitors for nitrogen and deplete soil nutrient pools (Craine et al. 2002; Oelmann et al. 2007). Therefore, whereas the carbon cycle was mainly affected by plant species richness and grass presence, the nitrogen cycle was affected by legume presence and less so by grass presence. This suggests that changes in functional composition should have a larger effect on nitrogen cycling than would changes in species richness. 


\section{Conclusions}

Our analysis, focused on measures from a single experiment, shows clear patterns of variation among biodiversity effects on a large number of different ecosystem functions. Taken together, our results stress that a wide variety of ecosystem functions will be at risk from local extinctions of plant species, but some will be more sensitive than others. In addition, further studies need to test whether the same ecosystem processes are strongly affected by biodiversity in managed systems where biodiversity responds to environmental change and affects ecosystem function. Our results emphasise the importance of considering a wide set of functions, and a broad range of measures representing those functions, in order to draw general conclusions in biodiversity-ecosystem functioning studies.

Our study indicates that the ability of ecosystems to sequester carbon will be particularly impaired by loss of plant species, as soil carbon storage in the soil was reduced in low diversity communities (Steinbeiss et al. 2008). Nutrient cycling will probably be less severely affected by plant species loss. In this case, direct effects of nitrogen deposition on nutrient cycling may be more severe than indirect effects mediated through changing species composition (Manning et al. 2006), although a loss of species from the particular functional group of legumes could have strong indirect effects. However, in more nitrogen-limited systems, where the plant species richness-biomass relationship is more likely to be driven by resource complementarity for nitrogen, loss of plant species richness might have larger effects on nitrogen cycling. In general, the strength of plant diversity effects on different types of ecosystem processes might depend on which factor drives the species richness-biomass relationship. Further comparative studies in other systems, comparing the strength of biodiversity effects between multiple processes measured in the same experiment, are needed to test this idea. We therefore hope that our findings stimulate further tests of the mechanisms underlying biodiversity effects in order to better understand variation in the strength of effects between different types of ecosystem processes.

\section{Acknowledgments}

We would like to thank Volker Kummer (supervised by MF), Peter Mwangi, Maike Habekost (supervised by GG), Yvonne Kreutziger (supervised by WW \& YO) and Ramona Müller (supervised 
by WV) for contributing data. The gardeners and technical staff who have worked on the Jena Experiment, for maintaining the site, weeding, mowing and data collection: Steffen Eismann, Steffen Ferber, Silke Hengelhaupt, Sylvia Junghans, Ute Köber, Katja Kunze, Heike Scheffler and Sylvia Creutzburg, Jens Kirchstein, Olaf Kolle, Gerlinde Kratzsch, Anett Oswald, Ulrike Wehmeier. We would also like to thank a large number of student helpers who were involved in the weeding of the experiment, Cornelius Middelhoff and Jens Schumacher for maintaining the database and JeanFrancois Soussana and Tania Jenkins for comments on earlier drafts of the manuscript. This project was funded by the Deutsche Forschungsgemeinschaft DFG with additional contributions from the Swiss National Science Foundation (grant 31003A-107531 to BS).

\section{References}

Allan E, van Ruijven J, Crawley MJ (2010) Foliar fungal pathogens and grassland biodiversity. Ecology 91:2572-2582.

Allan E, Weisser W, Weigelt A, Roscher C, Fischer M, Hillebrand H (2011) More diverse plant communities have higher functioning over time due to turnover in complementary dominant species. Proc Natl Acad Sci USA 108:17034-17039.

Baayen RH, Davidson DJ, Bates DM (2008) Mixed-effects modeling with crossed random effects for subjects and items. Journal of Memory and Language 59:390-412.

Balvanera P, Pfisterer AB, Buchmann N, He J, Nakashizuka T, Raffaelli D, Schmid B (2006) Quantifying the evidence for biodiversity effects on ecosystem functioning and services. Ecol. Lett. 9:1146-1156.

Bates D, Maechler M, Bolker BM (2011) Lme4: linear mixed-effects models using S4 classes $0.999375-42$.

Bessler H, Temperton VM, Roscher C, Buchmann N, Schmid B, Schulze E, Weisser WW, Engels C (2009) Aboveground overyielding in grassland mixtures is associated with reduced biomass partitioning to belowground organs. Ecology 90:1520-1530.

Blüthgen N, Klein A (2011) Functional complementarity and specialisation: The role of biodiversity in plant-pollinator interactions. Basic Appl. Ecol. 12:282-291. 
Borer ET, Seabloom EW, Tilman D (2012) Plant diversity controls arthropod biomass and temporal stability. Ecol Lett 15:1457-1464

Cardinale BJ, Matulich KL, Hooper DU, Byrnes JE, Duffy E, Gamfeldt L, Balvanera P, O’Connor MI, Gonzalez A (2011) The functional role of producer diversity in ecosystems. Am J Bot 98:572-592.

Cardinale BJ, Srivastava DS, Duffy JE, Wright JP, Downing AL, Sankaran M, Jouseau C (2006) Effects of biodiversity on the functioning of trophic groups and ecosystems. Nature 443:989-992.

Cardinale BJ, Wright JP, Cadotte MW, Carroll IT, Hector A, Srivastava DS, Loreau M, Weis JJ (2007) Impacts of plant diversity on biomass production increase through time because of species complementarity. Proc Natl Acad Sci USA 104:18123-18128.

Carson WP, Cronin JP, Long ZT (2004) A general rule for predicting when insects will have strong top-down effects on plant communities: on the relationship between insect outbreaks and host concentration. In: Weisser WW, Siemann E (eds) Insects and Ecosystem Function. SpringerVerlag, Berlin.

Craine JM, Tilman D, Wedin D, Reich P, Tjoelker M, Knops J (2002) Functional traits, productivity and effects on nitrogen cycling of 33 grassland species. Funct. Ecol. 16:563-574.

Crawley MJ (2007) The R Book. John Wiley and Sons Ltd., Chichester.

Deyn GB de, van der Putten WH (2005) Linking aboveground and belowground diversity. Trends Ecol. Evol. 20:625-633.

Eisenhauer N, Beßler H, Engels C, Gleixner G, Habekost M, Milcu A, Partsch S, Sabais AC, Scherber C, Steinbeiss S, Weigelt A, Weisser WW, Scheu S (2010) Plant diversity effects on soil microorganisms support the singular hypothesis. Ecology 91:485-496.

Eisenhauer N, Milcu A, Sabais AC, Bessler H, Brenner J, Engels C, Klarner B, Maraun M, Partsch S, Roscher C, Schonert F, Temperton VM, Thomisch K, Weigelt A, Weisser WW, Scheu S (2011) Plant Diversity Surpasses Plant Functional Groups and Plant Productivity as Driver of Soil Biota in the Long Term. PLoS One 6:e16055.

von Felten S, Hector A, Buchmann N, Niklaus PA, Schmid B, Scherer-Lorenzen M (2009) Belowground nitrogen partitioning in experimental grassland plant communities of varying species richness. Ecology 90:1389-1399. 
Fornara DA, Tilman D (2008) Plant functional composition influences rates of soil carbon and nitrogen accumulation. J. Ecol. 96:314-322.

Gurevitch J, Hedges LV (1999) Statistical issues in ecological meta-analyses. Ecology 80:1142-1149. Haddad NM, Crutsinger GM, Gross K, Haarstad J, Knops JM, Tilman D (2009) Plant species loss decreases arthropod diversity and shifts trophic structure. Ecol. Lett. 12:1029-1039.

Hector A, Schmid B, Beierkuhnlein C, Caldeira MC, Diemer M, Dimitrakopoulos PG, Finn JA, Freitas H, Giller PS, Good J, Harris R, Hogberg P, Huss-Danell K, Joshi J, Jumpponen A, Korner C, Leadley PW, Loreau M, Minns A, Mulder CP, O'Donovan G, Otway SJ, Pereira JS, Prinz A, Read DJ, Scherer-Lorenzen M, Schulze ED, Siamantziouras AS, Spehn EM, Terry AC, Troumbis AY, Woodward FI, Yachi S, Lawton JH (1999) Plant diversity and productivity experiments in European grasslands. Science 286:1123-1127.

Hector A, Bagchi R (2007) Biodiversity and ecosystem multifunctionality. Nature 448:188-190.

Hirose T, Werger MJ (1995) Canopy Structure and Photon Flux Partitioning among Species in a Herbaceous Plant Community. Ecology 76:466-474.

Hooper DU, Adair EC, Cardinale BJ, Byrnes JE, Hungate BA, Matulich KL, Gonzalez A, Duffy JE, Gamfeldt L, O/'Connor MI (2012) A global synthesis reveals biodiversity loss as a major driver of ecosystem change. Nature 486:105-108.

Hooper DU, Chapin FS, Ewel JJ, Hector A, Inchausti P, Lavorel S, Lawton JH, Lodge DM, Loreau M, Naeem S, Schmid B, Setala H, Symstad AJ, Vandermeer J, Wardle DA (2005) Effects of biodiversity on ecosystem functioning: a consensus of current knowledge. Ecol. Monogr. 75:3-35. Hooper DU, Vitousek PM (1998) Effects of plant composition and diversity on nutrient cycling. Ecol. Monogr. 68:121-149.

Isbell F, Calcagno V, Hector A, Connolly J, Harpole WS, Reich PB, Scherer-Lorenzen M, Schmid B, Tilman D, van Ruijven J, Weigelt A, Wilsey BJ, Zavaleta ES, Loreau M (2011) High plant diversity is needed to maintain ecosystem services Nature 477:199-202.

Jackson RB, Canadell J, Ehleringer JR, Mooney HA, Sala OE, Schulze ED (1996) A global analysis of root distributions for terrestrial biomes. Oecologia 108:389-411. 
Kroon H de, Hendriks M, van Ruijven J, Ravenek J, Padilla FM, Jongejans E, Visser EJ, Mommer L (2012) Root responses to nutrients and soil biota: drivers of species coexistence and ecosystem productivity. J. Ecol. 100:6-15.

Loreau M, Naeem S, Inchausti P, Bengtsson J, Grime JP, Hector A, Hooper DU, Huston MA, Raffaelli D, Schmid B, Tilman D, Wardle DA (2001) Biodiversity and Ecosystem Functioning: Current Knowledge and Future Challenges. Science 294:804-808.

Manning P, Newington JE, Robson HR, Saunders M, Eggers T, Bradford MA, Bardgett RD, Bonkowski M, Ellis RJ, Gange AC, Grayston SJ, Kandeler E, Marhan S, Reid E, Tscherko D, Godfray HC, Rees M (2006) Decoupling the direct and indirect effects of nitrogen deposition on ecosystem function. Ecol. Lett. 9:1015-1024.

Maron JL, Marler M, Klironomos JN, Cleveland CC (2010) Soil fungal pathogens and the relationship between plant diversity and productivity. Ecol. Lett. 14:36-41.

Marquard E, Weigelt A, Roscher C, Gubsch M, Lipowsky A, Schmid B (2009) Positive biodiversityproductivity relationship due to increased plant density. J. Ecol. 97:696-704.

Oelmann Y, Buchmann N, Gleixner G, Habekost M, Roscher C, Rosenkranz S, Schulze E, Steinbeiss S, Temperton VM, Weigelt A, Weisser WW, Wilcke W (2011) Plant diversity effects on aboveground and belowground N pools in temperate grassland ecosystems: Development in the first 5 years after establishment. Global Biogeochem. Cycles 25:GB2014.

Oelmann Y, Wilcke W, Temperton VM, Buchmann N, Roscher C, Schumacher J, Schulze ED, Weisser WW (2007) Soil and plant nitrogen pools as related to plant diversity in an experimental grassland. Soil Sci. Soc. Am. J. 71:720-729.

Pacala SW, Kinzig A (2001) Introduction to theory and the common ecosystem model. In: Kinzig A, Pacala S, Tilman D (eds) The functional consequences of biodiversity: empirical progress and theoretical extensions. Princeton Univ Pr, pp 169-174.

Palmborg C, Scherer-Lorenzen M, Jumpponen A, Carlsson G, Huss-Danell K, Hogberg P (2005) Inorganic soil nitrogen under grassland plant communities of different species composition and diversity. Oikos 110:271-282. 
Proulx R, Wirth C, Voigt W, Weigelt A, Roscher C, Attinger S, Baade J, Barnard RL, Buchmann N, Buscot F, Eisenhauer N, Fischer M, Gleixner G, Halle S, Hildebrandt A, Kowalski E, Kuu A, Lange M, Milcu A, Niklaus PA, Oelmann Y, Rosenkranz S, Sabais A, Scherber C, SchererLorenzen M, Scheu S, Schulze E, Schumacher J, Schwichtenberg G, Soussana J, Temperton VM, Weisser WW, Wilcke W, Schmid B (2010) Diversity Promotes Temporal Stability across Levels of Ecosystem Organization in Experimental Grasslands. PLoS One 5:e13382.

R Development Core Team (2010) R: A Language and Environment for Statistical Computing. R Foundation for Statistical Computing, Vienna, Austria.

Reich PB, Tilman D, Isbell F, Mueller K, Hobbie SE, Flynn DF, Eisenhauer N (2012) Impacts of Biodiversity Loss Escalate Through Time as Redundancy Fades. Science 336:589-592.

Roscher C, Kutsch WL, Schulze E (2011) Light and nitrogen competition limit Lolium perenne in experimental grasslands of increasing plant diversity. Plant Biology 13:134-144.

Roscher C, Schumacher J, Baade J, Wilcke W, Gleixner G, Weisser WW, Schmid B, Schulze ED (2004) The role of biodiversity for element cycling and trophic interactions: an experimental approach in a grassland community. Basic Appl. Ecol. 5:107-121.

Rosenberg M, Adams D, Gurevitch J (2000) Metawin 2.0 User's Manual: Statistical Software for Meta-Analysis. Sinauer Associates, Sunderland, MA.

Rosenkranz S, Wilcke W, Eisenhauer N, Oelmann Y (2012) Net ammonification as influenced by plant diversity in experimental grasslands. Soil Biol. Biochem. 48:78-87.

Rzanny M, Voigt W (2012) Complexity of multitrophic interactions in a grassland ecosystem depends on plant species diversity. J. Anim. Ecol. 81:614-627.

Scherber C, Eisenhauer N, Weisser WW, Schmid B, Voigt W, Fischer M, Schulze E, Roscher C, Weigelt A, Allan E, Beszler H, Bonkowski M, Buchmann N, Buscot F, Clement LW, Ebeling A, Engels C, Halle S, Kertscher I, Klein A, Koller R, Konig S, Kowalski E, Kummer V, Kuu A, Lange M, Lauterbach D, Middelhoff C, Migunova VD, Milcu A, Muller R, Partsch S, Petermann JS, Renker C, Rottstock T, Sabais A, Scheu S, Schumacher J, Temperton VM, Tscharntke T (2010) Bottom-up effects of plant diversity on multitrophic interactions in a biodiversity experiment. Nature 468:553-556. 
Scherer-Lorenzen M, Palmborg C, Prinz A, Schulze ED (2003) The role of plant diversity and composition for nitrate leaching in grasslands. Ecology 84:1539-1552.

Schmid B, Balvanera P, Cardinale BJ, Godbold J, Pfisterer AB, Raffaelli D, Solan M, Srivastava DS (2009) Consequences of species loss for ecosystem functioning: meta-analyses of data from biodiversity experiments. In: Naeem S, Bunker D, Hector A, Loreau M, Perrings C (eds) Biodiversity, Ecosystem Functioning, and Human Wellbeing An Ecological and Economic Perspective. Oxford University Press, Oxford.

Schnitzer SA, Klironomos JN, Hille Ris Lambers J, Kinkel LL, Reich PB, Xiao K, Rillig MC, Sikes BA, Callaway RM, Mangan SA, van Nes EH, Scheffer M (2011) Soil microbes drive the classic plant diversity-productivity pattern. Ecology 92:296-303.

Schulze ED, Zwölfer H (1994) Fluxes in Ecosystems. In: Schulze ED (ed) Flux control in biological systems: from enzymes to populations and ecosystems. Academic Press Inc.

Siemann E (1998) Experimental Tests of Effects of Plant Productivity and Diversity on Grassland Arthropod Diversity. Ecology 79:2057-2070.

Steinbeiss S, BeßLer H, Engels C, Temperton VM, Buchmann N, Roscher C, Kreutziger Y, Baade J, Habekost M, Gleixner G (2008) Plant diversity positively affects short-term soil carbon storage in experimental grasslands. Glob Change Biol 14:2937-2949.

Temperton VM, Mwangi PN, Scherer-Lorenzen M, Schmid B, Buchmann N (2007) Positive interactions between nitrogen-fixing legumes and four different neighbouring species in a biodiversity experiment. Oecologia V151:190-205.

Tilman D, Reich PB, Knops J, Wedin D, Mielke T, Lehman C (2001) Diversity and Productivity in a Long-Term Grassland Experiment. Science 294:843-845.

Tilman D, Reich PB, Isbell F (2012) Biodiversity impacts ecosystem productivity as much as resources, disturbance, or herbivory. Proc Natl Acad Sci USA 109:10394-10397.

Tilman D, Wedin D, Knops J (1996) Productivity and sustainability influenced by biodiversity in grassland ecosystems. Nature 379:718-720.

Vitousek PM, Howarth RW (1991) Nitrogen limitation on land and in the sea: How can it occur? Biogeochemistry 13:87-115. 
Table 1: The explanatory terms used in the analysis.

Six ecosystem process terms were used to group all 418 measurements into the categories shown. In addition to these terms, year and soil depth of measurement were included as continuous fixed terms.

\begin{tabular}{|c|c|}
\hline $\begin{array}{l}\text { Ecosystem } \\
\text { process term }\end{array}$ & Categories \\
\hline \multirow{3}{*}{$\begin{array}{l}\text { Biogeochemical } \\
\text { cycle }\end{array}$} & $\begin{array}{l}\text { Carbon: variables that are principally carbon, i.e. biomass and abundance measures, } \\
\text { carbon concentrations, and } \mathrm{CO} 2 \text { and } \mathrm{CH} 4 \text { emission rates. }\end{array}$ \\
\hline & $\begin{array}{l}\text { Nutrients: measures of nutrient concentrations in the soil and in plant biomass, } \mathrm{N}- \\
\text { related enzyme activities in soil, } \mathrm{N} 2 \mathrm{O} \text { emission rates, } 15 \mathrm{~N} \text { signals. }\end{array}$ \\
\hline & Water: measures of soil water. \\
\hline \multirow{5}{*}{$\begin{array}{c}\text { Trophic } \\
\text { Level }\end{array}$} & Producer: measures of plants. \\
\hline & $\begin{array}{l}\text { Herbivore: abundance and species richness of herbivore groups (including pollinating } \\
\text { insects and foliar fungal pathogens) and measures of herbivory. }\end{array}$ \\
\hline & Decomposer: abundance and species richness of decomposer groups. \\
\hline & Carnivore: abundance and species richness of carnivorous groups. \\
\hline & Ecosystem: abiotic measures. \\
\hline \multirow{2}{*}{ Compartment } & Above: all measures taken aboveground. \\
\hline & Below: all measures taken belowground. \\
\hline \multirow{2}{*}{$\begin{array}{l}\text { Diversity vs. } \\
\text { Other processes }\end{array}$} & Diversity: measures of animal and pathogen species richness. \\
\hline & Others processes: all other measures. \\
\hline \multirow{2}{*}{$\begin{array}{l}\text { Abiotic vs. } \\
\text { Biotic }\end{array}$} & $\begin{array}{l}\text { Abiotic: all abiotic measures: i.e. those which are not direct measures of organisms } \\
\text { but can include processes affected by organisms, such as soil nutrient levels. }\end{array}$ \\
\hline & $\begin{array}{l}\text { Biotic: all biotic measures: i.e. those which are direct measures of organisms such as } \\
\text { plant biomass or plant nutrient concentrations. }\end{array}$ \\
\hline \multirow{2}{*}{$\begin{array}{l}\text { Static vs. } \\
\text { Dynamic }\end{array}$} & Static: measures of pool sizes \\
\hline & Dynamic: measures of fluxes \\
\hline
\end{tabular}


Table 2: The significance of explanatory terms used in the analyses.

Explanatory terms were fitted in linear mixed-effects models with $Z r$-values for species richness, legume presence or grass presence effects as response variables (see Methods for description of the models). The table shows $\chi^{2}$ values from Likelihood ratio tests: the "+" columns are for the explanatory term fitted alone (i.e. added to the intercept only model) and values in the "-" columns are for terms deleted from a model containing all the other explanatory terms (Methods). Asterisks indicate significance: $*$ at $5 \% * * 1 \%$ and $* * * 0.1 \%,{ }^{\text {NS }}$ indicates non-significant effects; p-values $>0.05$ and $<0.08$ are shown. Values in bold are those that were significant on deletion and on addition, according to our strict criteria these are the only terms that are considered significant.

\begin{tabular}{|l|c|cc|cc|cc|}
\hline & & \multicolumn{2}{|c|}{ Species richness } & Legume presence & \multicolumn{2}{|c|}{ Grass presence } \\
\hline & $\begin{array}{c}\text { Degrees of } \\
\text { freedom }\end{array}$ & + & - & + & - & + \\
\hline Year & 1 & $\mathbf{7 . 4}^{* *}$ & $\mathbf{7 . 1}^{* *}$ & $0.1^{\mathrm{NS}}$ & $0.7^{\mathrm{NS}}$ & $\mathbf{5 . 1}^{*}$ & $\mathbf{6 . 8}^{* * *}$ \\
Space & 1 & $\mathbf{7 . 2}^{* *}$ & $\mathbf{6 . 7} * *$ & $0.08^{\mathrm{NS}}$ & $0.3^{\mathrm{NS}}$ & $1.0^{\mathrm{NS}}$ & $3.3^{0.07}$ \\
Trophic Level & 4 & $2.8^{\mathrm{NS}}$ & $1.1^{\mathrm{NS}}$ & $2.4^{\mathrm{NS}}$ & $0.2^{\mathrm{NS}}$ & $6.3^{\mathrm{NS}}$ & $4.3^{\mathrm{NS}}$ \\
Biogeochemical Cycle & 2 & $\mathbf{6 . 7}^{*}$ & $\mathbf{5 . 8}^{*}$ & $1.2^{\mathrm{NS}}$ & $3.4^{\mathrm{NS}}$ & $6.1^{*}$ & $3.1^{\mathrm{NS}}$ \\
Compartment & 1 & $2.4^{\mathrm{NS}}$ & $0.5^{\mathrm{NS}}$ & $4.2^{*}$ & $2.0^{\mathrm{NS}}$ & $1.3^{\mathrm{NS}}$ & $0^{\mathrm{NS}}$ \\
Diversity vs. Others & 1 & $\mathbf{1 0 . 7}^{* *}$ & $\mathbf{7 . 1}^{* *}$ & $1.7^{\mathrm{NS}}$ & $0^{\mathrm{NS}}$ & $0.6^{\mathrm{NS}}$ & $0.7^{\mathrm{NS}}$ \\
Abiotic vs. Biotic & 1 & $0.7^{\mathrm{NS}}$ & $0.5^{\mathrm{NS}}$ & $1.1^{\mathrm{NS}}$ & $0^{\mathrm{NS}}$ & $1.0^{\mathrm{NS}}$ & $0.4^{\mathrm{NS}}$ \\
Static vs. Dynamic & 1 & $0.01^{\mathrm{NS}}$ & $0.15^{\mathrm{NS}}$ & $2.1^{\mathrm{NS}}$ & $0.1^{\mathrm{NS}}$ & $1.4^{\mathrm{NS}}$ & $0.2^{\mathrm{NS}}$ \\
\hline
\end{tabular}




\section{Figure Legends}

Fig 1: The effect of (a) species richness and the presence of (b) legumes and (c) grasses on a range of ecosystem processes. All measures have been grouped according to the ecosystem process with which they are associated. Effect sizes, measured as $Z r$-values, are shown for the different ecosystem processes with $95 \%$ confidence intervals: ecosystem processes whose confidence intervals do not include 0 can be considered to be significantly affected by species richness or functional group presence. The size of the points is scaled according to the total number of measures taken per ecosystem process. Points represent estimates calculated from Markov Chain Monte Carlo (MCMC) sampling of terms from a linear mixed effect model with ecosystem process as a fixed effect and the random effect structure specified in equation 3 (Methods), MCMC means are very similar to the weighted means. Error bars represent 95\% confidence intervals calculated using MCMC sampling. Processes are grouped according to the biogeochemical cycle to which they belong (carbon, nutrient, water) these are separated by solid lines. Within the carbon variables, processes are grouped according to trophic level (producer, herbivore, decomposer, carnivore, ecosystem) these are separated by vertical dashed lines. Processes in red are those measured belowground and those in black were measured aboveground. Processes in blue are measures of diversity (all of these are also aboveground measures). Abbreviations are given for elements: carbon $(\mathrm{C})$ nitrogen $(\mathrm{N})$ and phosphorus $(\mathrm{P})$.

Fig. 2: Change in the size of species richness effects over time and soil depth. Average species richness $Z r$-values are shown for each a) year and b) soil depth. In both cases the solid line is the prediction from a linear mixed model with the random effect structure in equation 2 and with a) year and b) soil depth fitted as fixed effects. Dotted lines show \pm one standard error.

Fig. 3: Slopes showing the change in the strength of species richness effects ( $Z r$-values) on various ecosystem processes over a) time and b) soil depth. All processes which were measured in a) three or more years and b) three or more soil depths are shown. Points and $95 \%$ confidence intervals come from Markov Chain Monte Carlo MCMC sampling of mixed models. Mixed models were fitted with fixed effects: ecosystem process, year (in a) or soil depth (in b) and their interaction, i.e different 
slopes were estimated for each ecosystem process. Random effects were variable and the variable $\mathrm{x}$ year (factorial) interaction, see methods. Points are proportional to the number of measures taken for each ecosystem process (i.e. number of variables x number of times each variable was measured).

Fig. 4: The mean $Z r$-values and 95\% confidence intervals for species richness effects, shown for variables belonging to different biogeochemical cycles. a) The full analysis with all 418 measures and b) the reduced analysis with only the 181 direct measures of the different biogeochemical cycles, i.e. excluding those measures, such as plant biomass, which can be associated with more than one of the cycles. Points represent estimates calculated from Markov Chain Monte Carlo (MCMC) sampling of terms from a linear mixed effect model with biogeochemical cycle as a fixed effect and the random effect structure specified in equation 2 (Methods), MCMC means are very similar to the weighted means. Error bars represent 95\% confidence intervals calculated using MCMC sampling. 


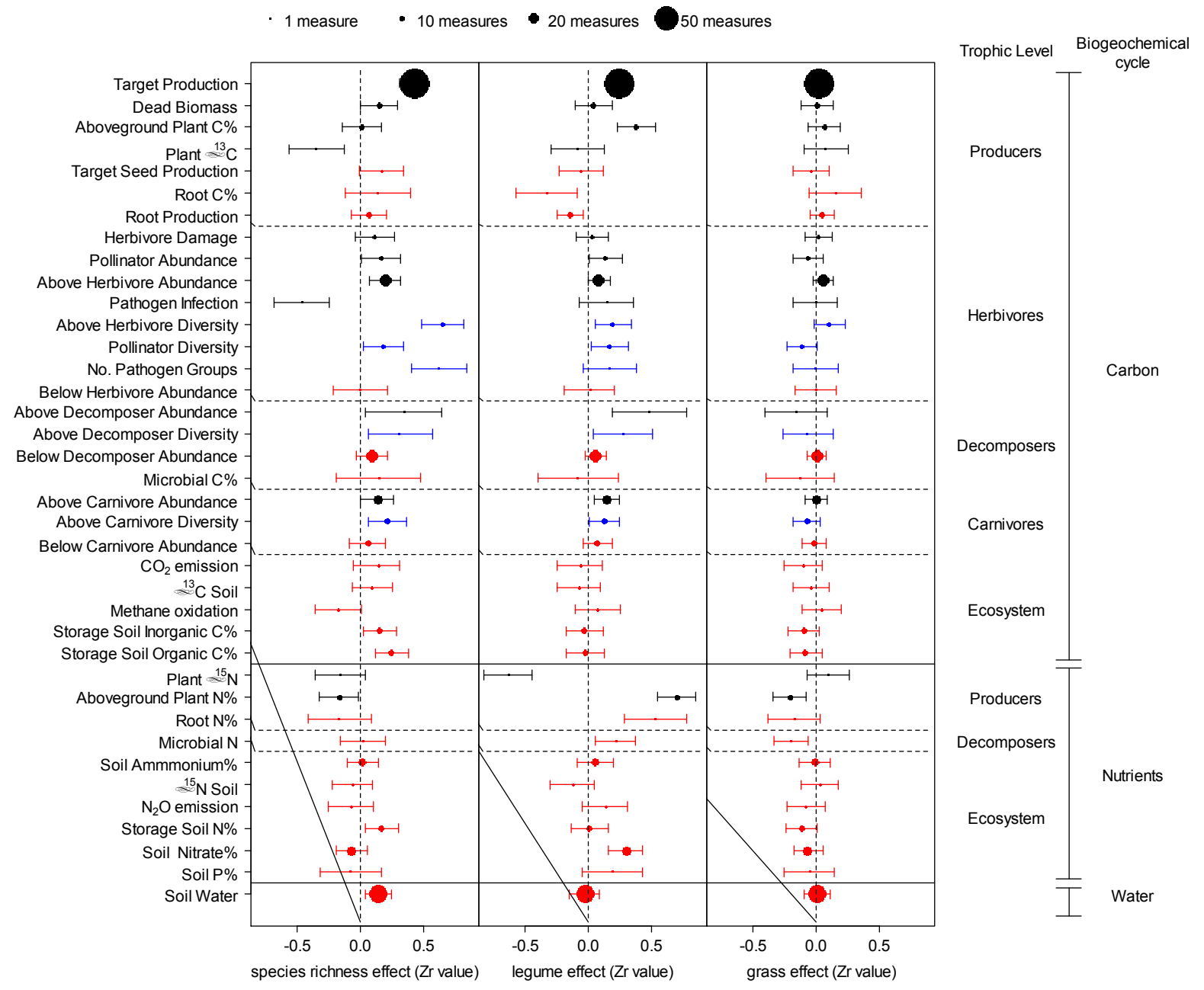

Fig 1 
a)

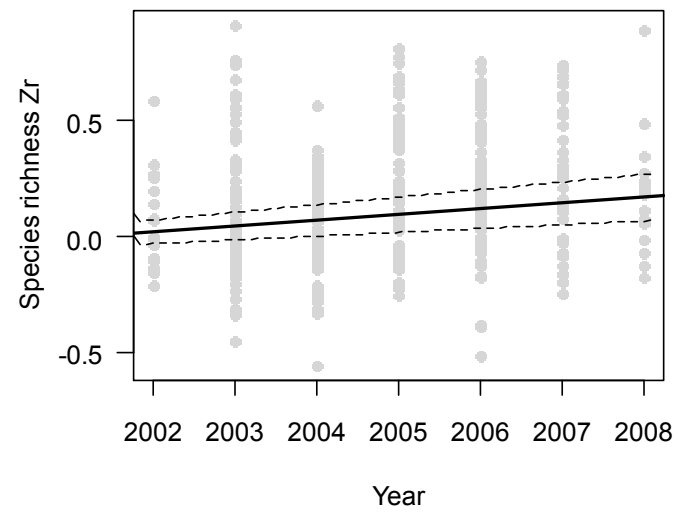

b)

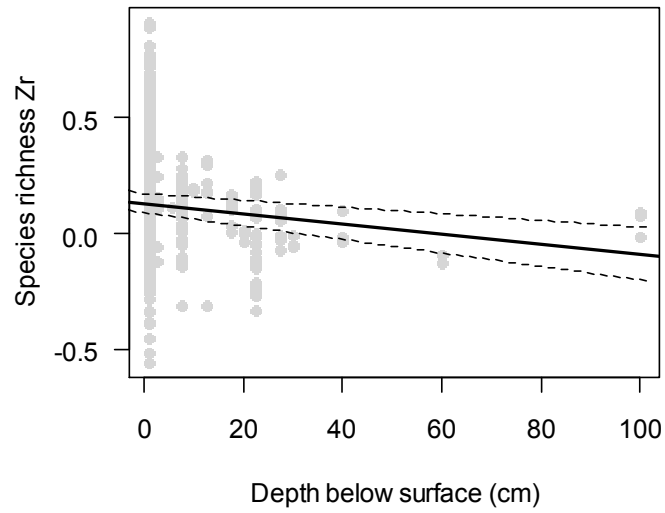

Fig. 2 

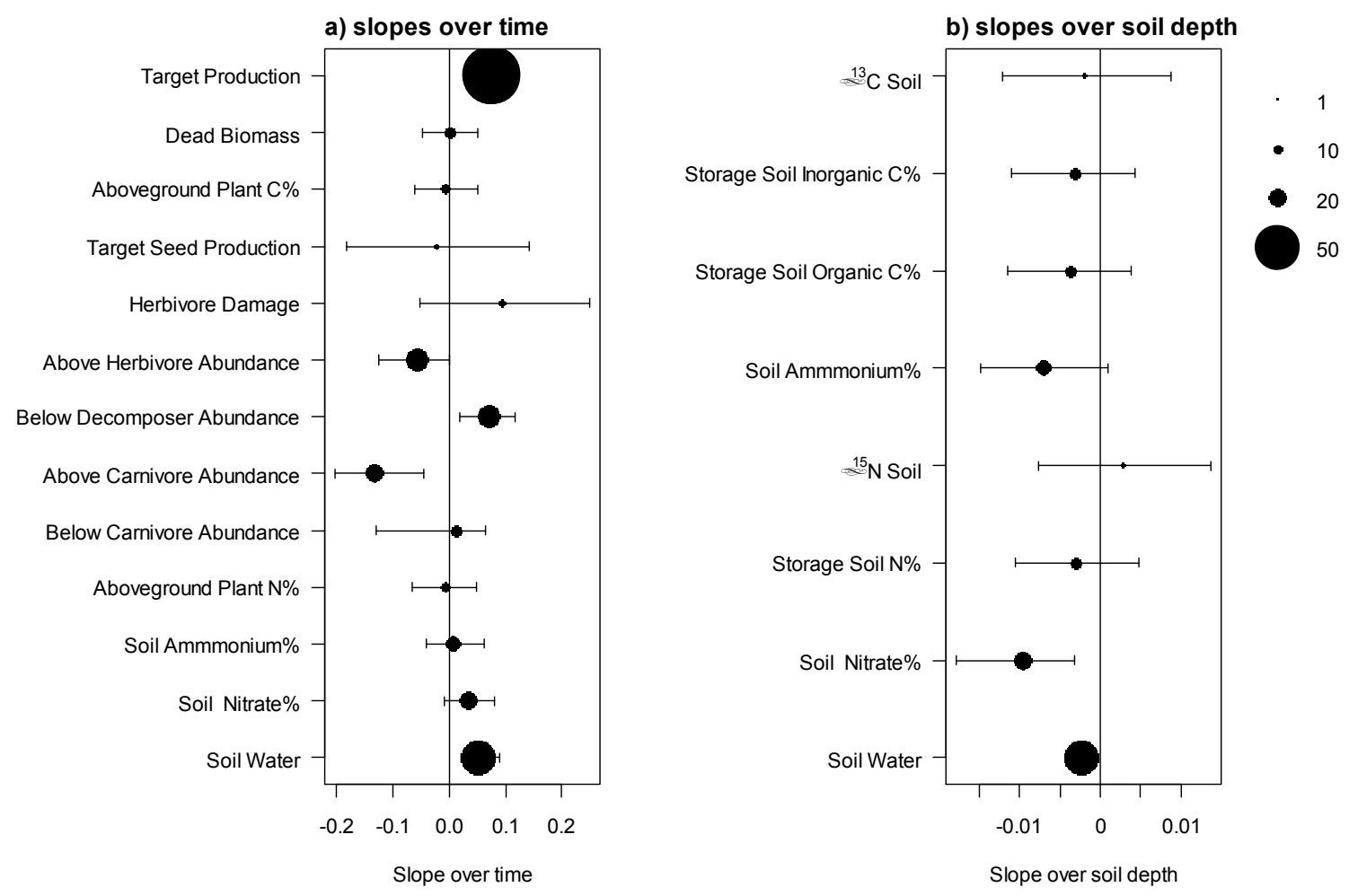

Fig. 3 
a) full analysis

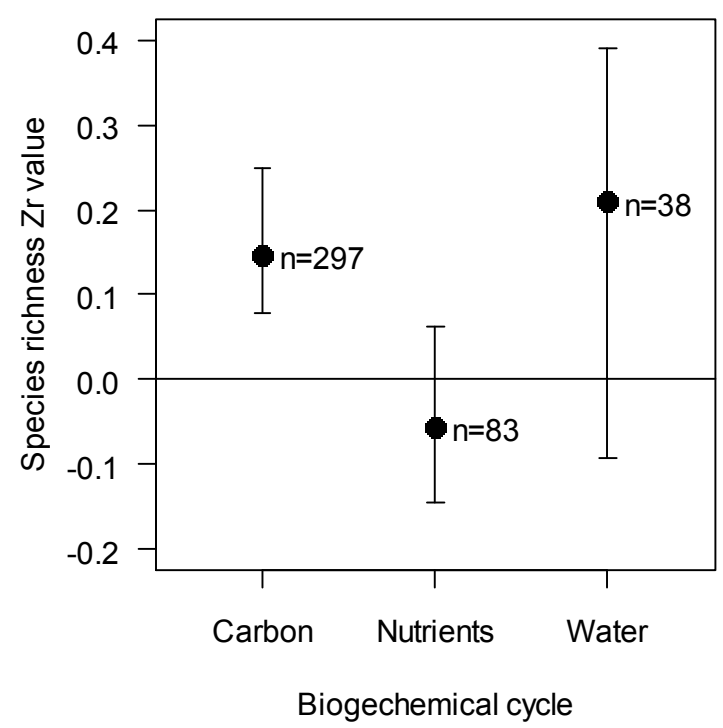

b) only direct measures

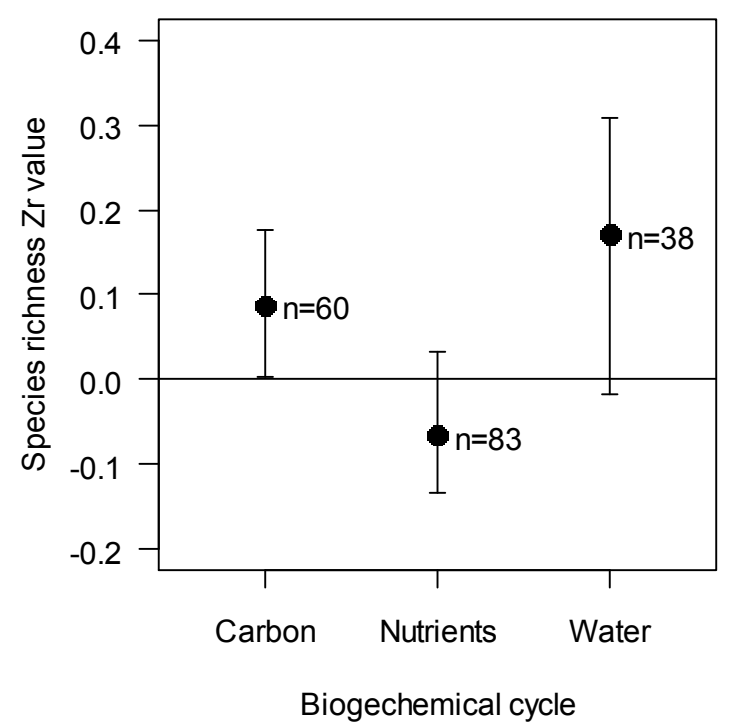

Fig. 4 